\title{
Electrochemical and In Situ Investigation of Quaternary Lithium Transition Metal Fluorides in Li-Ion Batteries
}

\author{
G. Lieser, C. Dräger, H. Geßwein, L. de Biasi, S. Glatthaar, S. Indris, H. Ehrenberg, M. J. Hoffmann, J. R. Binder
}

Institute for Applied Materials (IAM), Karlsruhe Institute of Technology

Helmholtz Institute UIm (HIU), Karlsruhe Institute of Technology

\section{Abstract}

Lithium transition metal fluorides are very promising materials compared to common oxide materials with corresponding electrochemically active cations because the more electronegative fluorine atoms increase the redox potential leading to a higher specific energy. However, no reports are given about the electrochemical properties of quaternary lithium transition metal fluorides as positive electrode. In this study, a novel sol-gel route was applied to synthesize several quaternary lithium transition metal fluorides $\mathrm{LiMFeF}_{6}\left(\mathrm{M}^{2+}=3 \mathrm{~d}\right.$ transition metal) without the use of toxic chemicals like $\mathrm{HF}$, LiF or $\mathrm{F}_{2}$. It is shown that up to 1 eq. lithium can be inserted fully reversible into the LiMFeF $_{6}$ host structure with a notable cycling stability and a remarkable rate performance. Furthermore, an in situ x-ray powder diffraction revealed that the host structure is an insertion material. The electrochemical active redox couple $\mathrm{Fe}^{3+/ 2+}$ was confirmed by Mössbauer analysis.

\section{Synthesis: TFA-Route a Novel Sol-Gel Process for quaternary Lithium Metal Fluorides}

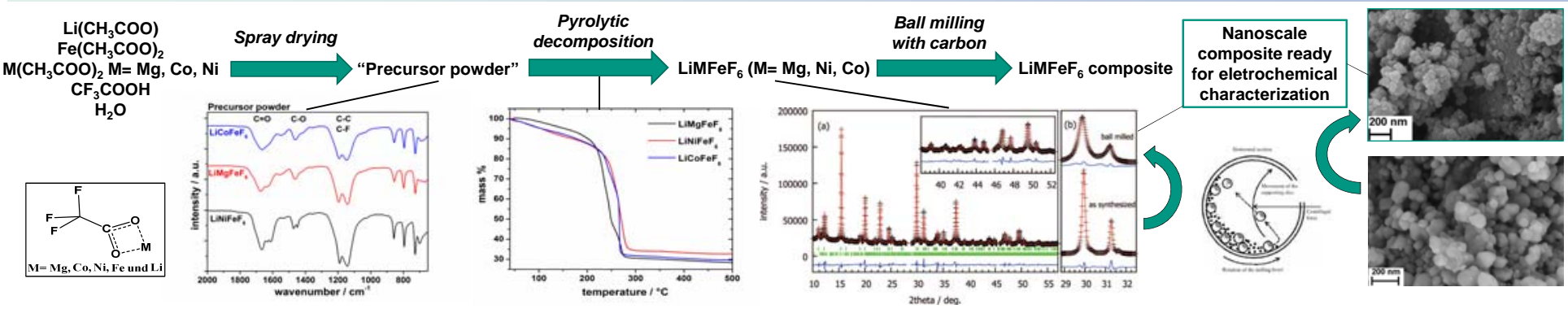

\section{Electrochemical Investigations}

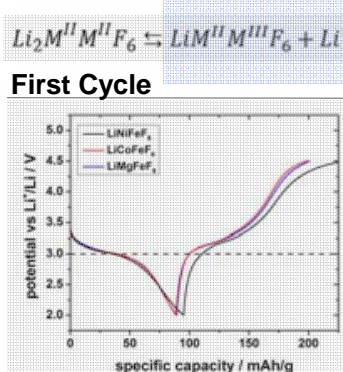

\. $M^{\prime \prime \prime} M^{\prime \prime \prime} F_{6}+2 L i^{+}+2 e$

Close to 1 eq. lithium can be cycled reversible

No reversible $\mathrm{M}^{3+} / \mathrm{M}^{2+}(\mathrm{M}=\mathrm{Co}, \mathrm{Ni})$ redox couple

Cycle Stability
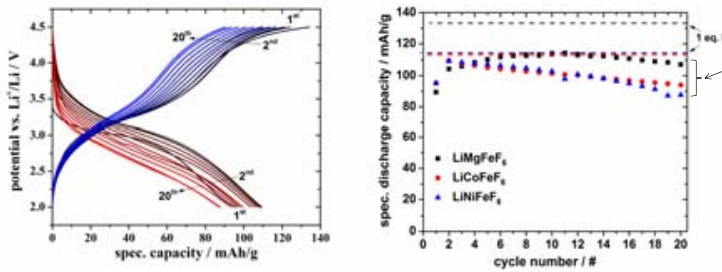

1 eq. lithium can be cycled reversible ( 20 cycles)

Similar capacity fade during cycling $\sim 1(\mathrm{mAh} / \mathrm{g}) / \mathrm{cycle}$ Rate Performance
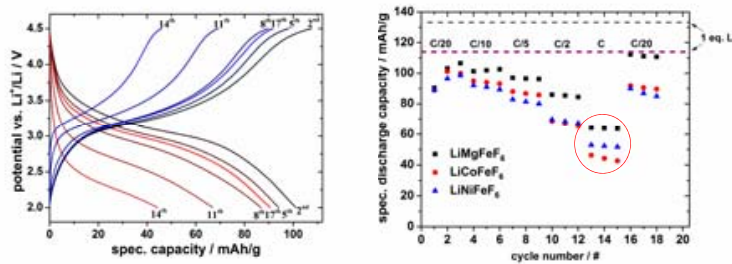

Half of the theoretical capacity even at $1 \mathrm{C}$ !

In Situ X-ray Powder Diffraction and Fe Mössbauer Analysis In situ investigation of $\mathrm{LiNiFeF}_{6}$ on a laboratory diffractometer

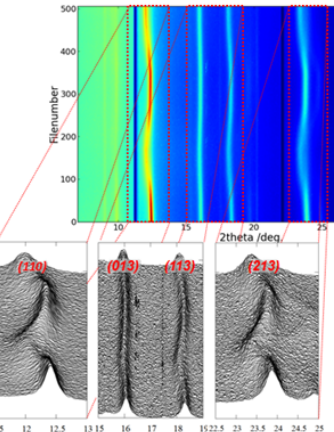

$2 \theta\left[^{\circ}\right.$

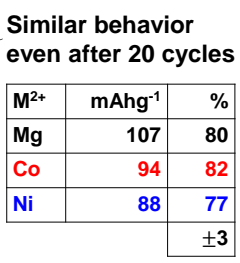

\begin{tabular}{|l|r|r|}
\hline $\mathbf{M}^{2+}$ & mAhg $^{-1}$ & $\%$ \\
\hline $\mathbf{M g}$ & 107 & $\mathbf{8 0}$ \\
\hline $\mathrm{Co}$ & 94 & 82 \\
\hline $\mathrm{Ni}$ & 88 & 77 \\
\hline \multicolumn{2}{|r}{} & \pm 3 \\
\cline { 2 - 3 }
\end{tabular}

\section{Conclusion}

Electrochemical properties of trirutile compounds is unaffected by the divalent cation.

At a discharge rate of $1 \mathrm{C}$ half of the specific discharge capacity was obtained.

Anisotropic lattice expansion of the host structure during cycling. The $\mathrm{Fe}^{3+} / \mathrm{Fe}^{2+}$ redox couple was confirmed by Mössbauer analysis. 